\title{
A Qualitative Study to Explore Patient Perspectives of Prophylactic Treatment with OnabotulinumtoxinA for Chronic Migraine
}

\author{
Igor Wilderman (D) · Deborah Tallarigo $\cdot$ Olga Pugacheva-Zingerman
}

Received: August 5, 2021 / Accepted: September 1, 2021 / Published online: September 14, 2021

(C) The Author(s) 2021

\begin{abstract}
Introduction: Onabotulinumtoxin A (OBT-A) is one of the most studied prophylactic treatments for chronic migraine. Large clinical trials, and now real-world studies, continue to provide evidence to support the use of OBT-A as an effective treatment to manage chronic migraine. The objective of this study was to explore patient experience and perception of prophylactic treatment with OBT-A for chronic migraine.

Methods: Data were collected using semistructured interviews using open-ended questions to uncover rich descriptive data on patient experiences. Interviews were transcribed and analysed using NVivo data analysis software to code and identify themes across the dataset. Three patient groups were included in the analysis: (1) patients who were receiving continued OBT-A treatment; (2) patients who discontinued OBT-A treatment; (3) patients who were recommended for OBT-A treatment but did not proceed.
\end{abstract}

Supplementary Information The online version contains supplementary material available at https:// doi.org/10.1007/s40122-021-00316-2.

I. Wilderman $(\bowtie) \cdot$ D. Tallarigo · O. PugachevaZingerman

Wilderman Medical Clinic, Thornhill, ON, Canada e-mail: iw@drwilderman.com
Results: For patients who received at least one OBT-A treatment, four main themes emerged, which described patients' expectations, experiences, and feelings towards their treatment decisions. Two main themes emerged that were common to patients, who had discontinued their treatment and those, who were recommended for OBT-A treatment but did not proceed, which were identified as potential barriers to initiate or continue prophylactic treatment with OBT-A.

Conclusion: Understanding patients' perspective is an important part of clinical practice and may impact on decision-making. Qualitative data can provide a more holistic view of patient care and treatment insights that may not be evaluated during a clinical trial. This study revealed potential barriers to treatment that can inform future policy and practice.

Keywords: Chronic migraine; OnabotulinumtoxinA; Botox; Patient perspectives; Lived experience; Prophylactic 


\section{Key Summary Points}

Currently, onabotulinumtoxinA (OBT-A) is the most used prophylactic treatment for chronic migraine

The objectives of this study were to explore patient experience and perception of prophylactic treatment with OBT-A for chronic migraine

Migraines were not eliminated in most patients in this study; however, patients viewed their treatment as effective as it made it easier to manage and go about daily tasks rather than being bed-ridden because of migraines and left unable to function

This study also revealed potential barriers to treatment, which include:

- Cost of injections: this was a significant factor in the decision-making process. Cost factors were voiced by almost every patient interviewed and were even the reason for some patients discontinuing treatment

- Fear associated with side effects and needles

These qualitative data provide a more holistic perspective of patient care when treating chronic migraine and insights that may not be evident from the results of a clinical trial. These factors should be taken into consideration to inform future policy and practice

\section{INTRODUCTION}

OnabotulinumtoxinA (OBT-A) via intramuscular injection is one of the most studied prophylactic treatments for chronic migraine [1]. OnabotulinumtoxinA acts at a molecular level to impair intraneuronal vesicular fusion, thereby modulating neuropeptide release and downregulating the receptors and ion channels that play an important role in nociception [2]. Clinical trials have confirmed the efficacy in addition to evidence of long-term safety and tolerability of OBT-A as a prophylactic treatment for patients with chronic migraine [3-6]. More recent studies have also demonstrated significant reductions in the number of headache and migraine days and improved patient quality of life in real-life clinical settings [7-9]. Current recommendations are for OBT-A to be offered to patients with chronic migraine as a prophylactic treatment aimed at increasing headache-free days and improving patient quality of life.

Investigating the patient's experience is increasingly viewed as an important part of pain research, in that, the individual experiences of patients have an impact on subjective experiences and thus complement the role of quantitative research in this field $[10,11]$. In this way, qualitative research can enhance the understanding of key questions and concepts, providing important insight into pain responses [10]. Lived experience and personal impact of chronic migraine cannot be measured by standardized pain questionnaires [12]; however, these perspectives and experiences are relevant and provide a whole-person picture that should be taken into account $[13,14]$. There has been limited research reporting on the lived experience of those with chronic migraine [12].

Given the positive results of recent long-term clinical trials and real-life clinical experiences with OBT-A as a prophylactic treatment for chronic migraine, we wanted to explore patient perspectives and whether these reveal insights into the treatment experience in a real-world setting, which can inform future practice.

\section{METHODS}

\section{Study Design}

We conducted a descriptive qualitative study, a method that is suited to a relatively understudied area of research, producing findings that remain closer to the data and are less interpretive or transformative $[15,16]$. 


\section{Participants}

This study was approved by Canadian SHIELD Ethics Review Board, OHRP registration IORG0003491, FDA registration IRB00004157, registered with CAREB, NCEHR, 501 Deerhurst Drive, Suite 102, Burlington, ON, L7L 5T1. The study was conducted in accordance with the Helsinki Declaration and the ethical principles for medical research involving human subjects. Participants were identified from the Electronic Medical Records at Wilderman Medical Clinic, Thornhill, Ontario, Canada. Participants were contacted by a research coordinator, inviting them to participate in the study. Patients who agreed to participate and gave informed consent were included in the study. No identifying information is included in this article.

The participants were purposively selected based on the following inclusion criteria. Patients were considered to have chronic migraine according the criteria of at least 15 headache days per month, for at least 3 consecutive months, with features of a migraine headache on at least 8 days per month. Participants were excluded from the study if they had a previous diagnosis of cognitive impairment, brain injury that was linked with their chronic migraine, epilepsy or other seizure disorders, trigeminal neuralgia, or schizophrenia. Patients, who were receiving or offered treatment with OBT-A had previously tried and failed a number of acute and preventative medications for chronic migraine. A total of 24 participants were recruited for the study, 2 of whom did not meet inclusion criteria. Of the remaining 22 patients, 10 were receiving continued prophylactic treatment with OBT-A. Seven patients had received at least one treatment session but had subsequently discontinued treatment. Five patients were recommended for OBT-A treatment but decided not to proceed with this treatment. Making use of these comparative groups adds strength to the study design, allowing for further investigation of patient perspectives, which may enable the identification of specific challenges or barriers to treatment with which to inform future decisions to better serve patients [17].

\section{Data Collection}

Data were collected using semi-structured interviews, which enabled appropriate focus during the interviews, while at the same time allowing the patients to meaningfully express their experiences. The interview guide (Supplementary Material) was designed to draw out the experiences of living with chronic migraine on a day-to-day basis, the reasons for treatment choices, and subsequent feelings and experiences of treatment choices. During the interviews, clarifying questions were used when appropriate to elucidate further understanding of the participants' experience. The semi-structured interview thus remained flexible, allowing the participants to express their experiences in their own way. Demographic data were collected from the patients' clinical records.

\section{Data Analysis}

The interviews were conducted by telephone, with only the interviewer (DT) and the participant present. The interviews were recorded and transcribed verbatim, with any identifying information removed. Due to the exploratory nature of the study, we used a thematic approach to analysis to provide a rich description of the entire dataset. Themes were identified using an inductive approach to the data. Thematic analysis was conducted according to the guidelines of Braun and Clarke [18]. The data were analysed by reading and re-reading each transcript to become familiar with the data and identifying features of the individual interviews, which may begin to form patterns of data. The data were coded using data analysis software (NVivo), coding over the entire dataset. Coding proceeded by moving iteratively back and forth over the entire dataset, constantly comparing codes and text. Individual codes were sorted into groups according to similar concepts or ideas, forming the potential themes and sub-themes. A theme was representative of a significant aspect of the experiences studied, which showed a pattern across the dataset. The themes and sub-themes were considered in conjunction with the entire 
dataset, ensuring that they adequately represented the coded data. As a means of establishing trustworthiness, an audit trail was maintained in addition to critical review and peer debriefing with researchers who were not involved in data collection or analysis. All transcripts were coded before any comparisons between the two groups were made. Data were first analysed as an entire dataset, and then each group was analysed separately to determine whether any differences in themes emerged between groups [19-21].

\section{RESULTS}

Participants described their lived experiences with chronic migraine and treatments for chronic migraine. A total of 22 participants were interviewed; patient characteristics are described in Table 1.

The following main themes and sub-themes were derived from the data analysis and are summarized in Fig. 1.

Table 1 Patient characteristics

\begin{tabular}{|c|c|c|c|c|}
\hline Patient no. & Patient group & Age & Male/female & Number of treatments \\
\hline 1 & Discontinued & 52 & $\mathrm{~F}$ & 6 \\
\hline 2 & Ongoing & 51 & $\mathrm{~F}$ & 14 \\
\hline 3 & Ongoing & 52 & $\mathrm{~F}$ & 1 \\
\hline 4 & Ongoing & 44 & $\mathrm{~F}$ & 15 \\
\hline 6 & Discontinued & 56 & $\mathrm{~F}$ & 1 \\
\hline 7 & Did not proceed & 47 & $\mathrm{~F}$ & 0 \\
\hline 9 & Ongoing & 60 & M & Unknown \\
\hline 12 & Ongoing & 58 & $\mathrm{~F}$ & 3 \\
\hline 15 & Ongoing & 40 & $\mathrm{~F}$ & 10 \\
\hline 16 & Discontinued & 34 & $\mathrm{~F}$ & 12 \\
\hline 17 & Ongoing & 41 & $\mathrm{~F}$ & 15 \\
\hline 21 & Ongoing & 51 & $\mathrm{~F}$ & 7 \\
\hline 22 & Ongoing & 55 & $\mathrm{~F}$ & 2 \\
\hline 24 & Discontinued & 29 & M & 3 \\
\hline 27 & Discontinued & 63 & $\mathrm{~F}$ & 20 \\
\hline 28 & Ongoing & 65 & $\mathrm{~F}$ & Unknown \\
\hline 31 & Discontinued & 55 & $\mathrm{~F}$ & 2 \\
\hline 32 & Did not proceed & 35 & $\mathrm{~F}$ & 0 \\
\hline 34 & Did not proceed & 38 & $\mathrm{~F}$ & 0 \\
\hline 36 & Discontinued & 69 & $\mathrm{~F}$ & 1 \\
\hline 37 & Did not proceed & 52 & $\mathrm{~F}$ & 0 \\
\hline 38 & Did not proceed & 42 & $\mathrm{~F}$ & 0 \\
\hline
\end{tabular}




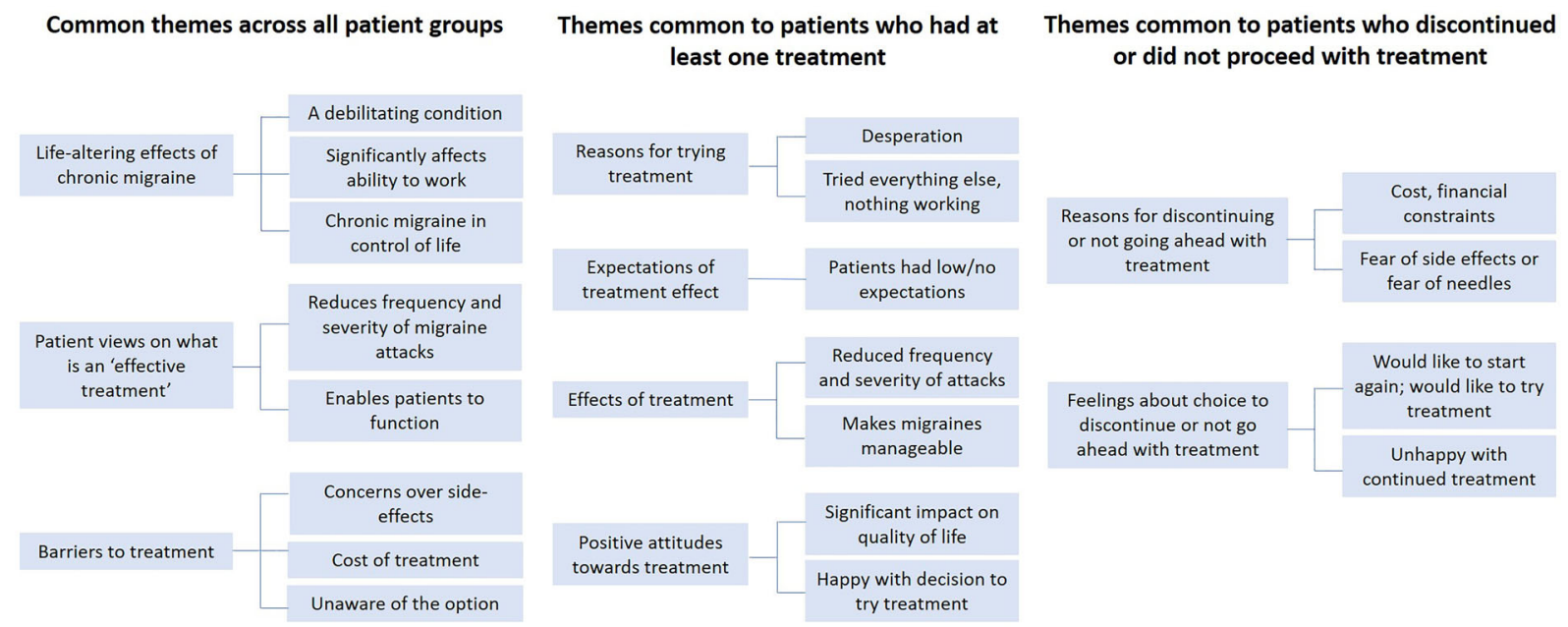

Fig. 1 Themes and sub-themes

\section{Common Themes Across Patient Groups}

Three major themes emerged when analysing the complete dataset including all patient groups: those, who were continuing with OBT-A treatment; those, who had at least one treatment but subsequently discontinued; those, who chose not to have OBT-A treatment.

\section{Life-Altering Effects of Chronic Migraine}

Patients described the effects of living with chronic migraine from their perspective and the impact on their daily lives. Three sub-themes were described regarding the life-altering effects of chronic migraine.

A Debilitating Condition Patients described their living with chronic migraine as almost completely debilitating and affecting every aspect of their life.

"... sometimes it makes me feel depressed because, um, the pain is debilitating and it makes it, um, it's like alters your enjoyment of life."

Patients spoke about how chronic migraine completely immobilizes them, keeping them bed-ridden for days at a time. They were unable to complete even basic daily tasks or take part in 'normal' activities.
"It prevents me from enjoying family functions that I miss, uh, like everyday life things that people do whether it's going grocery shopping or cleaning or meeting up with friends for a coffee or a drink."

Significantly Affects Ability to Work Participants also described the inability to carry out and function at a level required for holding a job or taking care of a family.

"... unable to go to work, unable to even really get out of bed, having to take pain medication and nausea medication and just really being, I would say, partially disabled from them."

Chronic Migraine in Control of Life Participants described how chronic migraine was controlling their life, how it made their life unpredictable, and that everything could change if a migraine began-making it impossible to plan.

"It prevents me from being able to plan long term, um, anything, you know, just being able to say, 'I will commit to being there on Thursday night', because I can't rely upon being fully functional." 


\section{Patient's Views on What an 'Effective Treatment' Is}

Patients described in their own words what they considered as 'effective'. Two major sub-themes emerged from the patients' perspectives regarding what they considered as an effective treatment.

Treatment that Reduces the Frequency and/or Severity of Migraine Attacks Most of the patients interviewed would consider a treatment effective if it reduced the frequency and/ or severity of migraine attacks. Most participants did not describe their view of 'effective' as something that would cure or completely stop any migraine attacks from occurring.

"I'm not asking the pain to be totally away but if it could decrease the frequencies and the, and the, the intensity I would be a happy camper."

Treatment that Provided Patients with an Ability to Function Patients also considered effective to mean that it would allow them to continue on with their daily activities and daily life, even if that meant that migraines were not completely gone.

"Less headaches, less pain...I could get through a day without, without my head between my knee, you know what I mean?"

\section{Barriers to OBT-A Treatment}

Our analysis revealed some potentially prohibitive factors that may prevent patients from deciding to have OBT-A treatment or being able to access a treatment that could potentially change their lives. These themes were described by all three patient groups.

Concerns over Side Effects Participants reported being concerned about potential side effects prior to starting OBT-A treatment. Typically, these were more to do with long-term side effects.

"But the only real reservation I had was the side effects, like long-term side effects."
Cost of Treatment The high cost of treatment was mentioned as a factor by most patients during at least one point in their interview.

"It's very expensive...I'm very fortunate that it's covered by my benefits...people who suffer from migraines, who don't have benefits, I think that's very unfortunate."

Even those who had private health benefits talked about the fact that some of the cost was covered, while a significant portion was still out of pocket.

"...my work covers most of my Botox. But then, the paying for the injection and, $u$, the balance is a lot of money."

Unaware of the Option/Would Like More Information Some participants spoke of the fact that they were initially unaware that OBT-A treatment was even an option for chronic migraine or that some physicians were unaware of the treatment. There was a certain sense of frustration over the general lack of knowledge of this treatment option.

"So, I will just say that, just need to have more information out there about that kind of treatment, because even my family doctor was not aware that Botox can be that kind of treatment for migraine."

Other patients expressed a genuine lack of understanding of how the treatment works to prevent chronic migraine; particularly given the fact that OBT-A is primarily known for its cosmetic effects, patients were unsure of how it could be effective to treat migraine.

"I'm just afraid of like, how is that supposed to do anything? How is that supposed to help a headache? What exactly is going into, what is being injected into me that stops a headache. Where does it go inside? Where, what is this stuff and where does it go to prevent me from a headache?" 


\section{Common Themes Among Patients Who Had at least One Treatment}

Four major themes were evident from the patients who had at least one OBT-A treatment, whether they went on to continue with treatment or discontinued treatment.

\section{Reasons for Trying OBT-A}

Three consistent sub-themes were evident from the patient interviews for those who had tried at least one treatment.

Desperation Participants described a sense of desperation for a treatment that would help them; they were unhappy with the pain management achieved with other modalities, which in most cases precipitated the decision to try OBT-A.

"I couldn't take the migraines anymore. Four or five times a week for two years, vomiting, it was really bad."

Tried Everything Else, Nothing Working The participants described the multiple medications and non-medicinal treatments that they had tried.

"I've tried, oh, gosh, let me think, I've tried so many things."

Although participants tried multiple and varied treatments, typically over a period of many years, many described how the treatments were not enough to keep them functioning at a satisfactory level and that they were not effective at keeping them healthy enough to stay out of bed.

"Nothing else was really working, I was getting worse instead of getting better."

\section{Low Expectations of OBT-A Treatment Effect}

Participants' expectations of OBT-A prior to commencing treatment were not unrealistic or high. Some patients described having no expectations at all.

"...I was skeptical to some degree because nothing else had worked...honestly, my expectations were probably low just because I tried so many things and nothing was working."

\section{Effects of OBT-A Treatment}

A major theme from the data analysis was surrounding the described treatment effect.

OBT-A Reduced Frequency and Severity Although the majority of patients did not see complete prevention of migraine episodes with OBT-A, they described how treatment significantly reduced the occurrence, severity, and/or intensity of migraine attacks.

"...and even now like I still get migraines occasionally like they the frequency is it's cut back, but also the severity."

Even though, for the most part, patients did not have a complete resolution of migraine attacks, they described the treatment as 'effective'.

"So compared to other treatments that I've had, I find, even though the migraine's not gone, it's an effective treatment."

\section{Makes the Migraines Manageable with Other} Medications Patients that reported still getting some migraine attacks described how these attacks were now manageable and amenable to treatment with other medications.

"... and because they were decreased tremendously, the drugs were far more effective in treating what I had...I would only have maybe a handful of migraines that were treatable with other drugs."

Participants further described that because the migraines were now manageable, they were able to continue to function even if a migraine should occur, as opposed to before OBT-A where it was completely debilitating and they would have to retreat to bed for days at a time. They described their ability to carry on with normal life, even in the event of a migraine.

"...when, once in a while, I was getting a headache I was still able to go work and everything to function when before, without the Botox, I was not able, I needed to take time 
off, or somebody needed to take care of the kids."

\section{Positive Attitudes Towards Decision to Have OBT-A Treatment}

Patients had positive attitudes towards the OBTA treatment, regardless of whether they had full resolution of migraines or whether they still had 'manageable' migraine occurrences.

Significant Impact on Quality of Life ('given me my life back') Most participants described a significant impact of treatment on their ability to function, how it completely changed their life, and how it gave them back a 'normal' life.

"[Botox injections] made a huge difference in my life. I feel like I do function like a regular human again."

Patients Were Happy with their Decision to Try OBT-A Participants described their decision to try OBT-A as the best decision they had made regarding their treatment.

"...it was the best decision that I made as far as anything to do with my, any of my treatments."

Some participants were very pleased with the treatment and described that they had wished they had known about it earlier,

"I wish I would've known about this two years ago. I would have done it right away."
Themes Common Among Patients Who Discontinued OBT-A or Did Not Try OBT-A at All

Two major themes that emerged from these patient groups were the reasons for either discontinuing treatment or not to going ahead with this treatment.

\section{Reasons for Discontinuing or Not Going Ahead with OBT-A}

The two major reasons for discontinuing treatment or deciding not to go ahead with treatment were consistent among both groups. These were:

Prohibitive Cost Participants reported stopping or not going ahead with OBT-A treatment because of the significant financial burden.

"I can't afford to keep paying for out of pocket every three months, I'm on a disability pension."

Fear of Side Effects and/or Fear of Needles Another common reason that patients described as a significant reason for discontinuing or not trying OBT-A was a fear of side effects or needles.

"I'm just, I'm actually terrified of just getting Botox."

The primary reason stated by each patient for not continuing with or not commencing OBT-A treatment is summarized in Table 2. Although

Table 2 Primary reason stated for discontinuing or not commencing OBT-A treatment

\begin{tabular}{lll}
\hline Reason & Number of patients & Patient group(s) \\
\hline Expense & 4 & Discontinued, did not proceed \\
Fear of side effects & 2 & Did not proceed \\
Fear of pain & 2 & Did not proceed \\
Side effects following treatment & 1 & Discontinued \\
Pain during injection & 1 & Discontinued \\
Lack of effect & 1 & Discontinued \\
Pregnancy & 1 & Discontinued \\
\hline
\end{tabular}


some patients stated more than one reason in their interview, these were identified as being the primary reason.

\section{Feelings About Choices to Discontinue or Not Go Ahead with OBT-A}

Two common themes were evident in terms of patients' feelings towards their decisions to either discontinue treatment or not go ahead with treatment.

Would Like to Start Again; Would Like to Try OBT-A Treatment Most patients expressed that they would like to have or resume OBT-A treatment. One patient expressed sadness over not being able to obtain a treatment that they knew was effective and, in their own words, 'life-changing'.

"I don't know if there's an appropriate word, but I'm sad, I wish that I could pay those hundreds of dollars every few months to have [Botox injections] because I would continue to do Botox."

Unhappy with Continued Treatments for Chronic Migraine For most of the patients who either stopped or did not try OBT-A, there was a general sentiment that they were not satisfied with the treatments they were continuing with. There was often a description that these treatments were not working as well and, in some cases, had more side effects than the OBT-A.

"I'm having side effects from the [treatment], where I never had any side effects from Botox."

\section{DISCUSSION}

This qualitative investigation of the patient experience adds nuance to the current evidence supporting use of OBT-A as a prophylactic, which can be used to inform patient-centred healthcare decisions [15]. Prophylactic treatment of chronic migraine with OBT-A continues to provide promising results in real-world studies; however, what has been missing is a focus on the patient experience and perceptions of treatment and treatment outcomes. These perspectives can help to provide a wholistic understanding of this treatment modality from which to inform evidence-based practice. To the best of our knowledge this is the first qualitative assessment of OBT-A as a prophylactic treatment for chronic migraine.

The lived experience and debilitating effects of chronic migraine described by patients in this study are consistent with previous research that has reported on the severe impact chronic migraine can have on work and family life [12, 22-24]. Our results are also consistent with a qualitative study reporting that chronic migraine patients do not expect to be completely pain free with treatment. Instead, they expect that pain severity and occurrence of migraines should be reduced [12]. Concordant with these expectations, there were generally very positive patient attitudes towards the effectiveness of OBT-A treatment in our patient group, even though migraines were not completely eliminated in the majority of patients in our study. For most patients, migraine attacks were not completely prevented by prophylactic OBT-A treatment; rather, the occurrence and/or intensity of migraine attacks was reduced. Consistent with Dekker et al. [25], the patients in our study reported being satisfied with treatment if it allowed them to continue 'normal' functioning at work or at home. This supports the notion that headache intensity is as important as frequency in the analysis of clinical response and related disability following prophylactic treatment with OBT-A [26]. Should these factors not be taken into consideration, treatment may be discontinued in patients who are experiencing life-changing benefits, even though certain clinical parameters may not be met [26]. Even though patients may not see benefits in terms of headache frequency, the impact on intensity alone can improve disability measures to the same extent; reducing severity can equate to as much as a $50 \%$ or more reduction in frequency [26]. The positive views of OBT-A treatment in our patient group may be a result of cumulative benefits that significantly improve patient quality of life [26]. These results support the need for qualitative research studies to accompany clinical efficacy studies. Patients may place more importance on factors 
other than clinical parameters that are typically measured in clinical trials. As suggested by Torres-Ferrus et al. [26], there is a need to establish the outcomes that are most significant to patients (such as tolerability) in order to effectively assess treatment responses in realworld settings. The combination of both qualitative and quantitative data will likely give the most meaningful results when it comes to patient satisfaction, perceived effects, and quality of life.

Previous clinical studies have demonstrated significant reductions in the use of other medications while being treated with OBT-A [27-30]. In our study, participants described how, following OBT-A treatment, the migraine attacks became manageable with other medications, allowing them to 'continue to function' with other medications. This is not only an important finding in the context of medication overuse, but the results also suggest that treating chronic migraine with OBT-A in combination with other drugs or treatment modalities may provide optimal benefit. Our findings, taken together with the clinical data, suggest that this is an area that requires further research.

Although a subset of patients may not respond to a first round of treatment with OBTA, it has been reported that some patients do respond in second or third cycles of treatment [31], demonstrating a need for continued treatment even if patients do not initially respond [32]. This improvement over time has been found to occur for up to 4 years in realworld clinical studies [33]. Three participants in our study group also described an increase in efficacy after more than one treatment. This should be considered when treating patients with OBT-A, particularly should patients decide to discontinue treatment because of perceived treatment failure. Improved communication with patients regarding these increasing benefits over time may prove helpful to encourage adherence beyond the first few treatments until an effect is seen.

A significant finding in our study was the impact of cost of OBT-A treatment. This was a factor mentioned by all patients, regardless of whether they were continuing with treatment, discontinued treatment, or chose not to proceed with treatment. In Ontario, the cost of OBT-A is only covered by public health insurance under the Exceptional Access Program. Private health insurance plans cover the cost of the medication itself, but neither public health nor private insurance cover the injection fee. This leaves patients with substantial costs, even if they have medication cost covered. Cost was prohibitive in 4 out of 12 cases, in which patients had to either refuse or discontinue treatment due primarily to cost factors. Previous studies have shown an economic cost benefit of OBT-A treatment in patients with chronic migraine [34, 35].

Other significant barriers uncovered in this study were the impact of fear of side effects and fear of pain associated with needles. This has previously been reported as the 'most important negative factor' associated with prophylaxis [25]. Fears of side effects or pain were the primary reasons stated for four out of five patients in this study, who chose not to proceed with OBT-A. Patient education strategies should aim to address these concerns in an effort to better inform patients about the potential side effects of treatment, as well as the potential benefits they may experience.

It is important to address some possible limitations in our study. The purposive sample was influenced by the availability of participants, which could potentially influence the results by including a sub-group of patients, who were poor responders to, or unhappy with, previous treatment strategies. However, there is some evidence to suggest that the more time after chronicity of migraine that passes, the less effective OBT-A might be [36]. Most patients in our study group had suffered with chronic migraine for many years prior to OBT-A treatment. In our patient sample, even though chronicity was likely reached many years prior to initiation of OBT-A, significant benefits were still noted. It is possible then that in a more randomly sampled population there may be even better response to treatment and therefore better perceptions and outcomes of treatment. Second, our study group consisted mostly of women, with only two men, which may not be representative of a larger clinical population. 
However, migraine is a condition that disproportionately affects women [37], so our sample may adequately represent this group of patients.

A strength of the current study was the inclusion of comparison groups, which can be used to uncover areas in need of specific support [17]. Including these comparison groups in our study added to rigour and reduced bias [38], in addition to improving understanding of patient perspectives and treatment decisions, which can be better used to inform evidence-based practice [17].

\section{CONCLUSIONS}

This study adds to the growing body of evidence supporting the use of OBT-A as a prophylactic treatment for chronic migraine. The results of our study add a unique, patient-centred perspective, highlighting the significant impact OBT-A can have on daily life, functioning, and management of chronic migraine. Our study supports the inclusion of qualitative analyses that provide an important dimension in patient care that is often unaccounted for in clinical trials. Overcoming the identified barriers to treatment should be a significant focus of policy and practice. Further investigation of economic impact and the possibility of the public healthcare system to cover cost of treatment are warranted. Our results also highlight areas in which to direct future research, in particular, investigation of OBT-A in combination with other treatments. Future research will enable patients to make more informed choices about the best way to manage their chronic migraine.

\section{ACKNOWLEDGEMENTS}

We thank the participants who took part in this study.

Funding. The study was funded by Wilderman Medical Clinic. The publication fees for this publication were covered by AbbVie.

Authorship. All named authors meet the International Committee of Medical Journal
Editors (ICMJE) criteria for authorship for this article, take responsibility for the integrity of the work as a whole, and have given their approval for this version to be published.

Authors' Contributions. IW, DT, and OP conceived this study. OP managed the database and participant recruitment. DT collected and analysed the qualitative data and drafted the manuscript. IW and OP provided critical review and peer debriefing throughout the data collection and analyses. IW and OP revised the paper for important intellectual content.

Prior Presentation. A part of this work was presented as a poster presentation at the Canadian Pain Society 2021 Annual Scientific Meeting (Virtual). Wilderman, I., Tallarigo, D., \& Pugacheva, O. (2021). A Qualitative Study to Explore Patient Perspectives of Prophylactic Treatment with Botox for Chronic Migraine. Poster Abstracts, Canadian Journal of Pain, 5:2, A48A137, DOI:10.1080/24740527.2021.1914233

Disclosures. Igor Wilderman, Deborah Tallarigo, and Olga Pugacheva-Zingerman declare that they have no conflict of interest.

Compliance with Ethics Guidelines. This study was approved by Canadian SHIELD Ethics Review Board, OHRP registration IORG0003491, FDA registration IRB00004157, registered with CAREB, NCEHR, 501 Deerhurst Drive, Suite 102, Burlington, ON, L7L 5T1. The study was conducted in accordance with the Helsinki Declaration and the ethical principles for medical research involving human subjects. Participants were contacted by a research coordinator, inviting them to participate in the study. Patients who agreed to participate and gave informed consent were included in the study. No identifying information is included in the manuscript.

Data Availability. The datasets generated during and/or analysed during the current study are available from the corresponding author on reasonable request. 
Open Access. This article is licensed under a Creative Commons Attribution-NonCommercial 4.0 International License, which permits any non-commercial use, sharing, adaptation, distribution and reproduction in any medium or format, as long as you give appropriate credit to the original author(s) and the source, provide a link to the Creative Commons licence, and indicate if changes were made. The images or other third party material in this article are included in the article's Creative Commons licence, unless indicated otherwise in a credit line to the material. If material is not included in the article's Creative Commons licence and your intended use is not permitted by statutory regulation or exceeds the permitted use, you will need to obtain permission directly from the copyright holder. To view a copy of this licence, visit http://creativecommons.org/licenses/by$\mathrm{nc} / 4.0 /$.

\section{REFERENCES}

1. Frampton JE, Silberstein S. OnabotulinumtoxinA: a review in the prevention of chronic migraine. Drugs. 2018;78(5):589-600. https://doi.org/10. 1007/s40265-018-0894-6.

2. Aurora SK, Brin MF. Chronic migraine: an update on physiology, imaging, and the mechanism of action of two available pharmacologic therapies. Headache. 2017;57(1):109-25. https://doi.org/10. 1111/head.12999.

3. Aurora SK, et al. OnabotulinumtoxinA for treatment of chronic migraine: results from the doubleblind, randomized, placebo-controlled phase of the PREEMPT 1 trial. Cephalalgia. 2010;30(7):793-803. https://doi.org/10.1177/0333102410364676.

4. Diener $\mathrm{HC}$, et al. OnabotulinumtoxinA for treatment of chronic migraine: results from the doubleblind, randomized, placebo-controlled phase of the PREEMPT 2 trial. Cephalalgia. 2010;30(7):804-14. https://doi.org/10.1177/0333102410364677.

5. Dodick DW, et al. OnabotulinumtoxinA for treatment of chronic migraine: pooled results from the double-blind, randomized, placebo-controlled phases of the PREEMPT clinical program. Headache J Head Face Pain. 2010;50(6):921-36. https://doi. org/10.1111/j.1526-4610.2010.01678.x.
6. Blumenfeld AM, Stark RJ, Freeman MC, Orejudos A, Manack Adams A. Long-term study of the efficacy and safety of OnabotulinumtoxinA for the prevention of chronic migraine: COMPEL study. J Headache Pain. 2018. https://doi.org/10.1186/ s10194-018-0840-8.

7. Schaefer SM, Gottschalk CH, Jabbari B. Treatment of chronic migraine with focus on botulinum neurotoxins. Toxins. 2015;7(7):2615-28. https://doi. org/10.3390/toxins 7072615 .

8. Ranoux D, Martiné G, Espagne-Dubreuilh G, Amilhaud-Bordier M, Caire F, Magy L. OnabotulinumtoxinA injections in chronic migraine, targeted to sites of pericranial myofascial pain: an observational, open label, real-life cohort study. J Headache Pain. 2017. https://doi.org/10.1186/s10194-0170781-7.

9. Hou $\mathrm{M}$, et al. Acupoint injection of onabotulinumtoxin a for migraines. Toxins. 2015;7(11): 4442-54. https://doi.org/10.3390/toxins7114442.

10. Mitchell LA, MacDonald RAR. Qualitative research on pain. Curr Opin Support Palliat Care. 2009;3(2): 131-5. 0b013e32832b7de2. https://doi.org/10.1097/SPC.

11. Flemming K, Adamson J, Atkin K. Improving the effectiveness of interventions in palliative care: the potential role of qualitative research in enhancing evidence from randomized controlled trials. Palliat Med. 2008;22(2):123-31. https://doi.org/10.1177/ 0269216307087319 .

12. Palacios-Ceña $D$, et al. Living with chronic migraine: a qualitative study on female patients' perspectives from a specialised headache clinic in Spain. BMJ Open. 2017. https://doi.org/10.1136/ bmjopen-2017-017851.

13. Webster LR, Harden RN. Why we need narratives of healing and qualitative pain research. Pain Med (United States). 2013;14(12):1811-2. https://doi. org/10.1111/pme.12291.

14. Peters M, Abu-Saad HH, Vydelingum V, Murphy M. Research into headache: the contribution of qualitative methods. Headache. 2002;42(10):1051-9. https://doi.org/10.1046/j.1526-4610.2002.02238.x.

15. Chenail RJ. How to conduct clinical qualitative research on the patient's experience. Qual Rep. 2011;16(4):1173-90. https://doi.org/10.46743/ 2160-3715/2011.1126.

16. Sandelowski M. Whatever happened to qualitative description? Res Nurs Health. 2000;23(4):334-40. https://doi.org/10.1002/1098-240X(200008)23:4\% 3c334::AID-NUR9\%3e3.0.CO;2-G. 
17. Lindsay S. Five approaches to qualitative comparison groups in health research: a scoping review. Qual Health Res. 2019;29(3):455-68. https://doi. org/10.1177/1049732318807208.

18. Braun V, Clarke V. Using thematic analysis in psychology. Qual Res Psychol. 2006;3(2):77-101.

19. Gorawara-Bhat R, O'Muircheartaigh S, Mohile S, Dale W. Patients' perceptions and attitudes on recurrent prostate cancer and hormone therapy: qualitative comparison between decision-aid and control groups. J Geriatr Oncol. 2017;8(5):368-73. https://doi.org/10.1016/j.jgo.2017.05.006.

20. Lindsay S, McAdam L, Mahendiran T. Enablers and barriers of men with Duchenne muscular dystrophy transitioning from an adult clinic within a pediatric hospital. Disabil Health J. 2017;10(1):73-9. https:// doi.org/10.1016/j.dhjo.2016.10.002.

21. Lysaker $\mathrm{PH}$, et al. Individual psychotherapy and changes in self-experience in schizophrenia: a qualitative comparison of patients in metacognitively focused and supportive psychotherapy. Psychiatry (New York). 2015;78(4):305-16. https://doi. org/10.1080/00332747.2015.1063916.

22. Leonardi M, Raggi A. A narrative review on the burden of migraine: when the burden is the impact on people's life. J Headache Pain. 2019;20(1):41. https://doi.org/10.1186/s10194-019-0993-0.

23. D'Amico D, Leonardi M, Grazzi L, Curone M, Raggi A. Disability and quality of life in patients with different forms of migraine. J Headache Pain. 2015;16(Suppl 1):1-2. https://doi.org/10.1186/ 1129-2377-16-S1-A4.

24. Lantéri-Minet M, Duru G, Mudge M, Cottrell S. Quality of life impairment, disability and economic burden associated with chronic daily headache, focusing on chronic migraine with or without medication overuse: a systematic review. Cephalalgia. 2011;31(7):837-50. https://doi.org/10.1177/ 0333102411398400 .

25. Dekker F, et al. Prophylactic treatment of migraine; the patient's view, a qualitative study. BMC Fam Pract. 2012;13:13. https://doi.org/10.1186/14712296-13-13.

26. Torres-Ferrus M, Gallardo VJ, Alpuente A, PozoRosich P. Influence of headache pain intensity and frequency on migraine-related disability in chronic migraine patients treated with OnabotulinumtoxinA. J Headache Pain. 2020;21(1):88. https://doi. org/10.1186/s10194-020-01157-8.

27. Russo $\mathrm{M}$, et al. The use of onabotulinum toxin $\mathrm{A}$ (Botox ${ }^{\circledR}$ ) in the treatment of chronic migraine at the Parma Headache Centre: a prospective observational study. Neurol Sci. 2016;37(7): 1127-31. https://doi.org/10.1007/s10072-0162568-z.

28. Kollewe $\mathrm{K}$, et al. Long-term treatment of chronic migraine with OnabotulinumtoxinA: efficacy, quality of life and tolerability in a real-life setting. J Neural Transm. 2016;123(5):533-40. https://doi. org/10.1007/s00702-016-1539-0.

29. Aurora SK, et al. OnabotulinumtoxinA for treatment of chronic migraine: pooled analyses of the 56-week PREEMPT clinical program. Headache. 2011;51(9):1358-73. https://doi.org/10.1111/j. 1526-4610.2011.01990.x.

30. Stark C, et al. Real-world effectiveness of onabotulinumtoxinA treatment for the prevention of headaches in adults with chronic migraine in Australia: a retrospective study. J Headache Pain. 2019;20(1):81. https://doi.org/10.1186/s10194-019. 1030-z.

31. Silberstein SD, et al. OnabotulinumtoxinA for treatment of chronic migraine: PREEMPT 24-week pooled subgroup analysis of patients who had acute headache medication overuse at baseline. J Neurol Sci. 2013;331(1-2):48-56. https://doi.org/10.1016/j. jns.2013.05.003.

32. Aurora SK, et al. OnabotulinumtoxinA for chronic migraine: efficacy, safety, and tolerability in patients who received all five treatment cycles in the PREEMPT clinical program. Acta Neurol Scand. 2014;129(1):61-70. https://doi.org/10.1111/ane. 12171.

33. Santoro A, Copetti M, Miscio AM, Leone MA, Fontana A. Chronic migraine long-term regular treatment with onabotulinumtoxinA: a retrospective real-life observational study up to 4 years of therapy. Neurol Sci. 2020;41(7):1809-20. https://doi. org/10.1007/s10072-020-04283-y.

34. Batty AJ, et al. The cost-effectiveness of onabotulinumtoxinA for the prophylaxis of headache in adults with chronic migraine in the UK. J Med Econ. 2013;16(7):877-87. https://doi.org/10.3111/ 13696998.2013 .802694 .

35. Ruggeri M. The cost effectiveness of Botox in Italian patients with chronic migraine. Neurol Sci. 2014;35(SUPPL):1. https://doi.org/10.1007/s10072014-1741-5.

36. Tassorelli C, et al. Optimizing the long-term management of chronic migraine with onabotulinumtoxinA in real life. Expert Rev Neurother. 2018;182: 167-76. https://doi.org/10.1080/14737175.2018. 1419867. 
37. Ray Dorsey E, et al. Global, regional, and national burden of Parkinson's disease, 1990-2016: a systematic analysis for the Global Burden of Disease Study 2016. Lancet Neurol. 2018;17(11):939-53. https://doi.org/10.1016/S1474-4422(18)30295-3.
38. Tomlin G, Borgetto B. Research pyramid: a new evidence-based practice model for occupational therapy. Am J Occup Ther. 2011;65(2):189-96. https://doi.org/10.5014/ajot.2011.000828. 